\title{
Cervical Cancer-A Tragedy We Can Prevent
}

World Health Organization (WHO) launched Global Strategy to spur up elimination of cervical cancer on $17^{\text {th }}$ Nov $2019^{1}$ by their Teal lighting initiative - this was the first ever global initiative towards elimination of cervical cancer with 194 countries committing to cancer elimination. The iconic landmarks stood in solidarity to illuminate in teal - and look at a cervical cancer free future. Standing in solidarity with over 100 landmarks across the world, In Amritsar in India from where I belong - the Golden Temple Plaza (entry to Golden Temple, Heritage walk, Jallianwala Bagh, Town Hall glimmered as beacons of hope for a cervical cancer free future - made possible by efforts of 'Phulkari CAN -Women of Amritsar'.

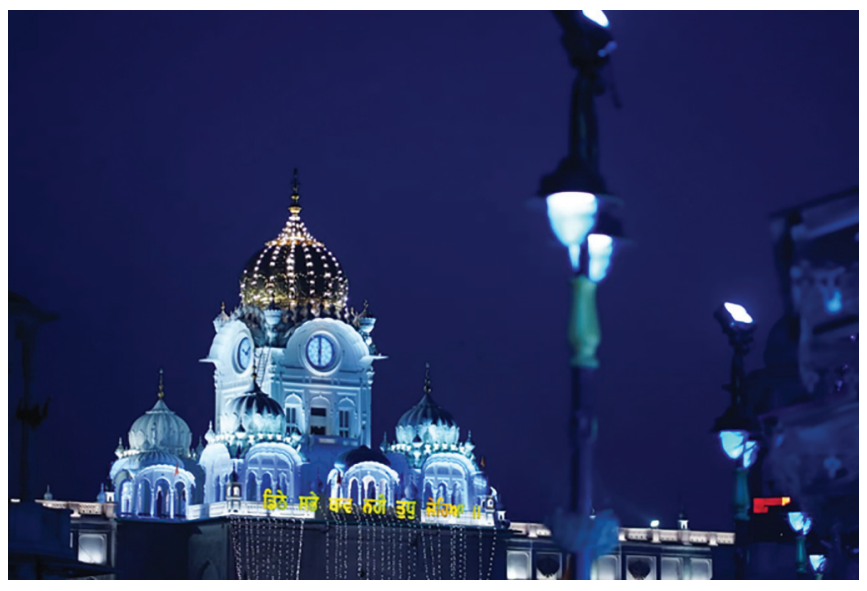

Three key strategies have been outlined under this WHO initiative: - Vaccination, Screening and Elimination. The discussion on Cervical cancer has become so pertinent at this hour. Reasons -

- Womens health especially during the Covid pandemic has been ignored and undermined - and this is a worldwide phenomenon.

- Cervical Cancer is preventable.

- $\quad$ Detected early it is treatable.

The WHO is focusing on Awareness, Vaccination and Screening - the three pillars to eliminate cervical cancer. The need of the hour is to create awareness and knowledge about what is cervical cancer, what are the causal factors and what can be done to eliminate it. Cervical cancer is one of the most treatable form of cancer, if it is detected early and managed effectively. It is the $4^{\text {th }}$ most common cancer in women in the world. 2018 data shows 5,70,000 women diagnosed with cervical cancer worldwide and about 3,11,000 women deaths. $90 \%$ deaths are seen in low and middle income countries while $80 \%$ of cervical cancer patients are detected in advanced stage of cancer. ${ }^{2,3}$

Cervical Cancer is the second most common cause of cancer mortality among women of low and middle income countries including India. ${ }^{4}$ Cervical cancer kills roughly 67,477 Indian women annually. Women in age group 55-65 age group are at the highest risk of Cervical cancer, many women also fall prey to it at 30's and even late 60's. 2018 stats show that there are 96,922 new cases and 60,078 deaths each year in India, accounting for one-fourth of world's cervical cancer deaths.

About $99.7 \%$ cases of cervical cancer are caused by high risk Human papilloma virus (HPV). About $60 \%$ sexually active men and women are infected with HPV sometime in their lives. Most HPV infections resolve spontaneously but persistent infections can cause cervical cancer. HPV types 16 and 18 are responsible for $82 \%$ of cervical cancers in India. Higher income countries have reduced their burden of this cancer by $65 \%$ over the past four decades by HPV vaccination and Screening campaigns ${ }^{5}$. HPV vaccine has played a major role in reducing the burden of this disease. Prof Harald zur Huasen in 2008 received the Nobel Prize in Physiology and Medicine for his avant-garde work on discovering the association between HPV and Cervical cancer - such is the implication of this discovery.

WHO has set targets for 2030 in a step towards elimination of cervical cancer':

- $\quad 90 \%$ girls fully vaccinated with HPV vaccine by 15 years of age.

- $\quad 70 \%$ women screened for cervical cancer with high performance test by age 35 and again by 45 years of age.

- $90 \%$ women detected receive treatment.

- If this target is met than by 2030 we can reduce cervical cancer deaths by $30 \%$ and bring down $40 \%$ of new cases and 5 million deaths by 2050.

3 HPV vaccines are available for use in USA : Gardasil ${ }^{\mathrm{R}}$, Gardasil ${ }^{\mathrm{R}} 9$ and Cervarix ${ }^{\mathrm{R}}$. All 3 prevent infection with HPV type 16 and 18, two high risk HPVs that cause about 70\% of cervical cancers (HPV 2). Cervarix ${ }^{R}$ also prevent infection from HPV types 6 and 11 (HPV4) which account for $90 \%$ of genital warts and Gardasil ${ }^{R} 9$ from HPV type 31,33,45,52 and 58 (HPV 9). 
The dose schedule for vaccine is:

- Age 9-14 years: 2 doses given at 0 and 6 months.

- Age 15-45 years: 3 doses given at 0, 2 and 6 months.

American Cancer Society updated guidelines for Cervical cancer screening: 6

- Age 25-29: HPV test every 5 years (preferred), HPV/PAP cotest every 5 years (acceptable), PAP test every 3 years (acceptable).

- Age 30-65: HPV test every 5 years (preferred), HPV/PAP cotest every 5 years (acceptable), PAP test every 3 years (acceptable).

- Age 65 and older: No screening if a series of prior tests were normal.

Focus should also shift to availability and use of self sampling kits for cervical screening in low and middle income countries like India, which would accelerate cervical screening program especially in the wake that several studies have authenticated that HPV DNA detection between self-collected vaginal samples have $98.9 \%$ sensitivity and $100 \%$ specificity vis a vis physician collected samples ${ }^{7}$.

The human papilloma virus (HPV) vaccination was launched in the districts of Bathinda and Mansa in Punjab by Principal Secretary Health, Mrs Vini Mahajan on 23 November 2016, with technical support from WHO Country Office for India. The state is waiting for the inclusion of HPV vaccination in the immunization programme throughout the state.

The Indian Academy of Paediatrics and Federation of Obstetrics and Gynaecology of India have strongly recommended the use of HPV Vaccination towards Cervical Cancer elimination, but we are still waiting to see its inclusion in the UIP of India. National Technical Advisory Group on Immunization (NTAGI) on a meeting on 19th Dec 2017 recommended for introduction of HPV vaccine. India specific data on cost effectiveness of HPV vaccines is also very promising according to WHO definition for inclusion in UIP. While HPV vaccine should be given to both boys and girls, but at present giving it to adolescent girls alone is more cost effective to reduce the disease burden. Giving that vaccination alone does not mitigate the need of Screening in later years of life. ${ }^{8}$

The investment in this project can generate huge economic and societal returns especially improving women's health also leading to improvement in family, community and societal well-being. We need governments and ministries of health and family welfare, Health care professionals, NGOs, partners, cancer advocates to come forward and adopt the WHO call towards prevention and elimination of cervical cancer.

After the success of implementation of COVID vaccination by India, if a cost effective indigenous HPV vaccine can be developed in India, NTAGI recommends and the vaccine is included in UIP, awareness of cervical screening and its implementation will definitely change the momentum from the debate on why to how India should implement its Cervical cancer elimination program. Let us all together create history and ensure a cervical cancer free future.

\section{References}

1. Fadela Chaib/WHO. A cervical Cancer-free future: First-ever global commitment to eliminate a cancer [internet]. Geneva:WHO;2020.[cited Dec 15 2020] Available from: http://www.who.int/news/item/17-11-2020-a-cervical-cancer-free-future-first-ever-global-commitment-to-eliminate-acancer.

2. Arbyn M, Weiderpass E, Bruni L, de Sanjosé S, Saraiya M, Ferlay J, Bray F. Estimates of incidence and mortality of cervical cancer in 2018: a worldwide analysis. Lancet Glob Health. 2020 Feb;8(2):e191-e203. doi: 10.1016/S2214-109X(19)30482-6. Epub 2019 Dec 4. PMID: 31812369; PMCID: PMC7025157.

3. Bray F, Ferlay J, Soerjomataram I, Siegel RL, Torre LA, Jemal A. Global cancer statistics 2018: GLOBOCAN estimates of incidence and mortality worldwide for 36 cancers in 185 countries. CA Cancer J Clin 2018; 68: 394-424. 2 PATH. Global HPV Vaccine Introduction Overview: projected and current national introductions, demonstration/pilot projects, gender-neutral vaccination programs, and global HPV vaccine introduction maps (2006-2022). November, 2019. https://www.path.

4. Kadam Y, Dhobale R, Gore A, Tripathi N. Barriers for early detection of cancer amongst Indian rural women. South Asian J Cancer. 2014; 3(2): 122. DOI: https://doi.org/10.4103/2278-330X.130449.

5. Jemal A, Center MM, DeSantis C, Ward EM. Global Patterns of Cancer Incidence and Mortality Rates and Trends. Cancer Epidemiol Biomarkers Prev. 2010; 19(8): 1893-1907. DOI: https://doi.org/10.1158/1055-9965.EPI-10-0437

6. Fontham, ETH, Wolf, AMD, Church, TR, Etzioni, R, Flowers, CR, Herzig, A, Guerra, CE, Oeffinger, KC, Shih, Y-CT, Walter, LC, Kim, JJ, Andrews, KS, DeSantis, CE, Fedewa, SA, Manassaram-Baptiste, D, Saslow, D, Wender, RC, Smith, RA. Cervical cancer screening for individuals at average risk: 2020 guideline update from the American Cancer Society. CA Cancer J Clin. 2020: 70: 321- 346. https://doi.org/10.3322/caac.21628

7. Santhosh Kuriakose, Sasidharanpillai Sabeena, Binesh Damodaran, N. Ravishankar, Amrutha Ramachandran, Nurul Ameen, Comparison of two selfsampling methods for human papillomavirus (HPV) DNA testing among women with high prevalence rates, Journal of Medical Virology, 10.1002/ jmv.26043, 92, 12, (3884-3888), (2020).

8. Minutes of the Meeting of the National Technical Advisory Group on Immunization (NTAGl), December 19, 2017. https://mohfw.gov.in/sites/ default/files/Approved\%20Minutes\%20of\%20 NTAGI\%20meeting\%20held\%20on\%20December\%2019\%202017.pdf

Richa Ghay Thaman Editor, CTDT 